\title{
MULTIFOCAL MOTOR NEUROPATHY: CASE REPORTS
}

\author{
Edin Jusufović, Osman Sinanović, Sanela Zukić, Adnan Burina, \\ Zlatka Džinić Jusufović and Alma Šakić \\ Department of Neurology, Tuzla University Clinical Centre, Faculty of Medicine, \\ University of Tuzla, Tuzla, Bosnia and Herzegovina
}

\begin{abstract}
SUMMARY - Multifocal motor neuropathy (MMN) is a chronic demyelinating neuropathy mainly characterized by multifocal distribution; affecting only motor nerve fibers of two or more peripheral nerves, with the absence of symptoms and signs of upper motor neuron; chronic, sometimes cascading progressive course; demyelination with partial block of motor conduction; immune-mediated pathogenesis and good response to intravenous immunoglobulin treatment (IVIG). The diagnosis of MMN is based on clinical, laboratory and electrophysiological characteristics. Steroids are ineffective in MMN and may lead to worsening of the disease. Similarly, therapeutic plasma exchange is negligibly effective in this neuropathy. However, more than $80 \%$ of patients with MMN experience improvement after IVIG. We present our three cases of MMN with positive response to IVIG.
\end{abstract}

Key words: Polyneuropathies; Demyelinating diseases; Peripheral nerves; Motor neurons; Immunoglobulins, intravenous

\section{Introduction}

Multifocal motor neuropathy (MMN) is an acquired, chronic, immune-mediated demyelinating neuropathy. Parry and Clark were the first to describe the disease discovered in five different patients in 1982 as a chronic, demyelinating, and sensorimotor multiple mononeuropathy. Later, in 1988, Pestronk and associates introduced the term "multifocal motor neuropathy" and they discovered the MMN connection with anti-GM1 IgM antibodies and positive response to immunomodulatory therapy. Since then, clinical and electrophysiological evaluation of large cohorts of $\mathrm{pa}^{-}$ tients have increased our understanding of the pathophysiology of MMN and paved the way for more effective treatment ${ }^{1-4}$.

The main clinical feature of $\mathrm{MMN}$ is slow progressive or cascading, asymmetric, predominantly distal

Correspondence to: Prof. Osman Sinanovic, PhD, Department of Neurology, Tuzla University Clinical Centre, Faculty of Medicine, University of Tuzla, 75000 Tuzla, Bosnia and Herzegovina

E-mail: osman.sinanovic@ukctuzla.ba

Received July 14, 2015, accepted August 22, 2017 extremity weakness without objective loss of sensation in the distribution of two or more peripheral nerves without signs of upper motor neuron lesion ${ }^{1,3}$. MMN is a rare disease with a frequency of $1-2 / 100000$. It is more common in men than in women at a ratio of about $3: 1$. About $80 \%$ of people experience the first symptoms between the ages of two and five decades of life. The average age at onset is 40 years ${ }^{1}$. MMN mainly affects younger people. Upper extremities are usually affected more often and more seriously than the lower ones $^{4}$. Proximal weakness is manifested in only 5\%$10 \%$ of MMN cases. The most common initial symptom is weakness of the wrist (wrist drop), as well as weakness of the hand grip. Muscle weakness is usually mild but can progress and it is usually associated with poor response to therapy. Other symptoms that may occur are fasciculations and muscle picks noted in about $50 \%$ of cases. The main characteristic of MMN is the lack of sensory symptoms. Only a few patients complain of discrete paresthesia or a feeling of numbness in the limbs. In about $20 \%$ of cases, there is minor disturbance of vibratory sensitivity. Tendon reflexes of 
weakened muscles are usually reduced but may be normal or rarely even lively. Cranial nerve involvement is uncommon and, if present, it predominantly affects hypoglossal nerve.

Diagnosis is based on history data, clinical picture and electromyoneurography (EMNG) as the gold standard. A marker is multifocal conduction block (CB) on EMNG testing ${ }^{1,2,4,5}$. Conduction block is reduction in the amplitude and area of compound muscle action potential (CMAP) obtained from the proximal point of stimulation compared to the CMAP obtained from the distal point of peripheral nerve. Generally, CB will appear when an incoming action potential at the level of Ranvier's node is unable to induce sufficient depolarization in the next sub-segments that would generate further action potential. The basis of $\mathrm{CB}$ formation is focal demyelination experimentally demonstrated in rodents. Apart from demyelination, axonal lesions may occur as well. Studies have indicated a functional role in the disintegration of the axonal impairment of the axon-myelin interaction.

In addition to $\mathrm{CB}, \mathrm{EMNG}$ testing can indicate the speed of conduction deceleration, prolongation of distal latency and F-responses as well.

To be diagnosed with MMN, CB must be established in at least two peripheral nerves ${ }^{1,4,5}$. Laboratory tests show a high titer of IgM anti-GM1 ganglioside antibodies that are recorded in $30 \%-80 \%$ of patients; however, negative finding does not exclude $\mathrm{MMN}^{1}$. Slightly elevated levels of creatine kinase can be found in two-thirds of patients. Cerebrospinal fluid in MMN usually is of normal composition, or occasionally may exhibit slight increase in protein concentration (up to $80 \mathrm{mg} / \mathrm{dL}$ ) and the reference number of cells.

Magnetic resonance imaging (MRI) in 50\% of cases may demonstrate enhancement of the T2 signal intensity in a part of the brachial plexus (if upper extremity is affected). In the future, MRI can become an elegant and noninvasive tool for assessing the integrity of the proximal nerve segments, bearing in mind that abnormal findings on MRI are usually asymmetric and the technique can help in differentiating MMN from chronic inflammatory demyelinating polyneuropathy, which is characterized by abnormal MRI finding that is mostly symmetric, as well as from the lower motor neuron diseases, where MRI findings are normal ${ }^{1,4}$. Nerve biopsy is rarely necessary to distinguish between $\mathrm{MMN}$ and nerve tumor or vasculitis. A biopsy can show nerve demyelination, bulb formation and axonal atrophy ${ }^{4}$.

The treatment of choice is intravenous administration of immunoglobulin (IVIG) in a dose of $0.4 \mathrm{~g} / \mathrm{kg} /$ day for two to five days ${ }^{1,4,6,7}$. After an initial therapeutic effect, depending on the clinical picture dynamics, it is recommended to repeat the same dose of $0.2 \mathrm{~g} / \mathrm{kg} / \mathrm{day}$ in 15-30 days or the originally specified dose every one to two months. The clinical effect of IVIG is impressive and muscle power is usually quickly repaired in the first week after administration of the first dose. However, the effect of therapy is partly reduced after a few weeks. The effectiveness of IVIG decreases naturally with age, and higher doses or shorter intervals between doses are usually needed. Recently, tests of effectiveness of applications of higher initial doses of IVIG to prevent secondary degeneration of axons and increased remyelination are being carried out and they are yet to be explained in larger studies in the period to come.

Subcutaneous IG application is advantageous for providing steadier plasma concentration of IG and thus better quality of life, while the economic aspect would not be negligible as well. This possibility should be additionally analyzed in the future.

In MMN cases when IVIG is not effective, cyclophosphamide is the next recommendation ${ }^{4}$. Cyclophosphamide has so far been tested in several small, uncontrolled studies. It was concluded that high doses of cyclophosphamide had a moderate effect, especially when administered intravenously, whereas oral administration showed no significant effect on the progression of the disease. However, cyclophosphamide is not recommended as a treatment by one group of experts because there is an opinion of the short-term and long-term toxicity and lack of evidence for efficiency in $\mathrm{MMN}^{4}$. We present our three cases of MMN.

\section{Case Reports}

\section{Case 1}

M.M., a 14-year-old boy, had a feeling of weakness in the left foot, which lasted for about two months. Neurologic examination revealed inability of dorsiflexion of the left foot with hypotrophy of $m$. extensor digitorum brevis (MEDB). Plantar flexion was possible, as well as supporting on the left toes. Patellar reflexes were symmetrically vivid. Left Achilles reflex was re- 


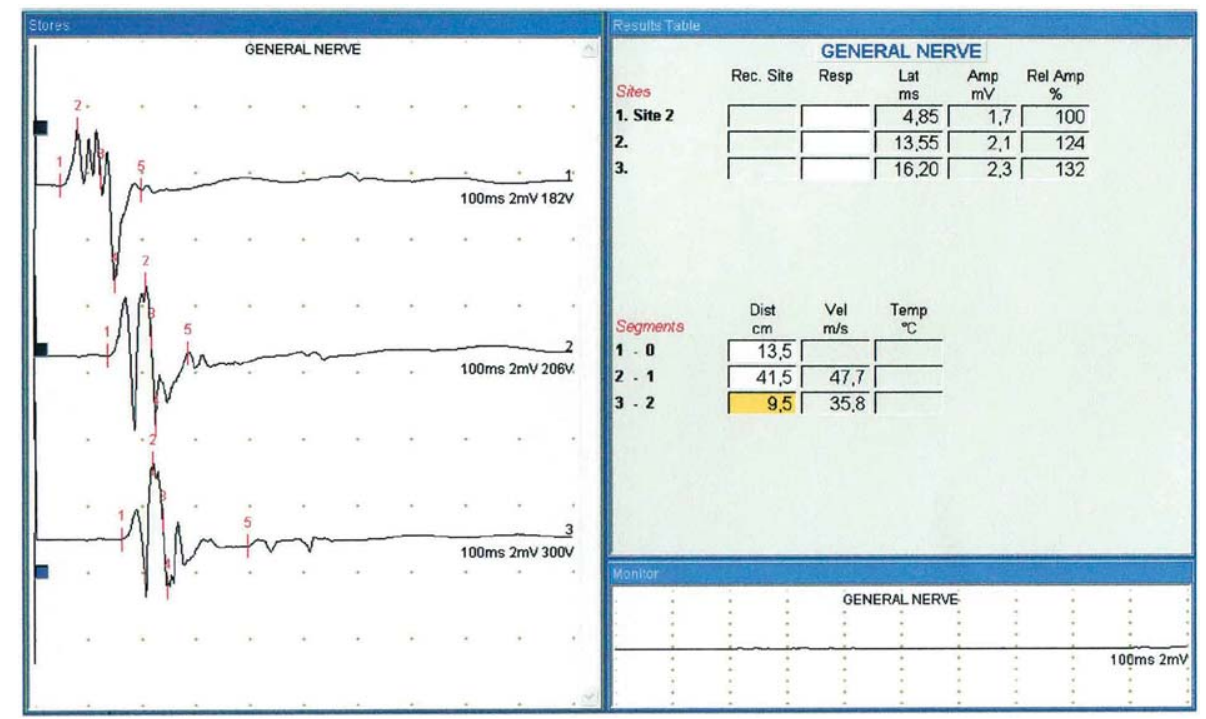

Fig. 1. Left sciatic nerve (n. tibialis), plurisegmental analysis of motor conduction velocity (partial conduction block).

duced. Sensitivity was neat. He could not stand up from squat on full feet. He walked with left peroneal weakness.

Electromyoneurography testing revealed a milder loss of motor neurons in the analyzed m. abductor digiti minimi analyzed on the right hand, with normal findings in other muscles of the right hand. The muscles of his left leg showed a significant loss of motoneurons in all muscles analyzed, up to denervation in the left MEDB. EMNG findings in the muscle of the right leg were completely normal. Motor conduction velocity $(\mathrm{MCV})$ on plurisegmental analysis, through all segments of the right ulnar nerve was normal, as well as through both deep peroneal and left femoral nerve. MCV through the sciatic nerve in the segment before the fork was slightly reduced, but was normal through tibial nerve. This nerve showed a possibility of partial CB (Fig. 1).

After the initial immunoglobulin i.v. application at a dose of $0.4 \mathrm{~g} / \mathrm{kg}$ body weight per day for five consecutive days, minimal improvement of neurologic deficit was observed. Weakness of the left leg was still present, but it was reduced. Plantar flexion showed much better power compared to the previous finding. Minimal activation of the foot extensor was possible. After physical treatment and administration of the second dose of immunoglobulin, additional improvement of neurologic deficit was evident. Plantar flexion of the left foot was possible to middle position, while walking was still clearly peroneal. After the third dose of IVIG, walking was practically normal. He could squat relatively correctly, standing up without difficulty but could not squat on full feet. Left Achilles tendon was shortened. Active dorsiflexion of the left foot and against resistance, as well as dorsiflexion and plantar flexion of the toes was almost normal. Left MEDB was less voluminous and slightly smaller than the right one. Patellar reflexes were symmetric and appropriate. Achilles reflexes were symmetric and appropriate.

Follow up EMNG performed one month after the third dose of IVIG indicated partial CB. MCV of the left ischiadic nerve (tibial nerve) was normal in the segment through tibial nerve and slightly reduced in the proximal segment over the crossroads on the terminal branches, and partial $\mathrm{CB}$ was recorded when the nerve was stimulated at its most proximal point.

\section{Case 2}

B.A., a 19-year-old boy, felt weakness in his left foot. Six months before, while playing football, he raised his left leg and then felt weakness and clumsiness in the left foot. He did not pay much attention to this event. Two months later, his parents noticed his problem. They noticed that he could not raise the left toe. He denied feeling pain in his left leg or back pain or any other symptoms. 


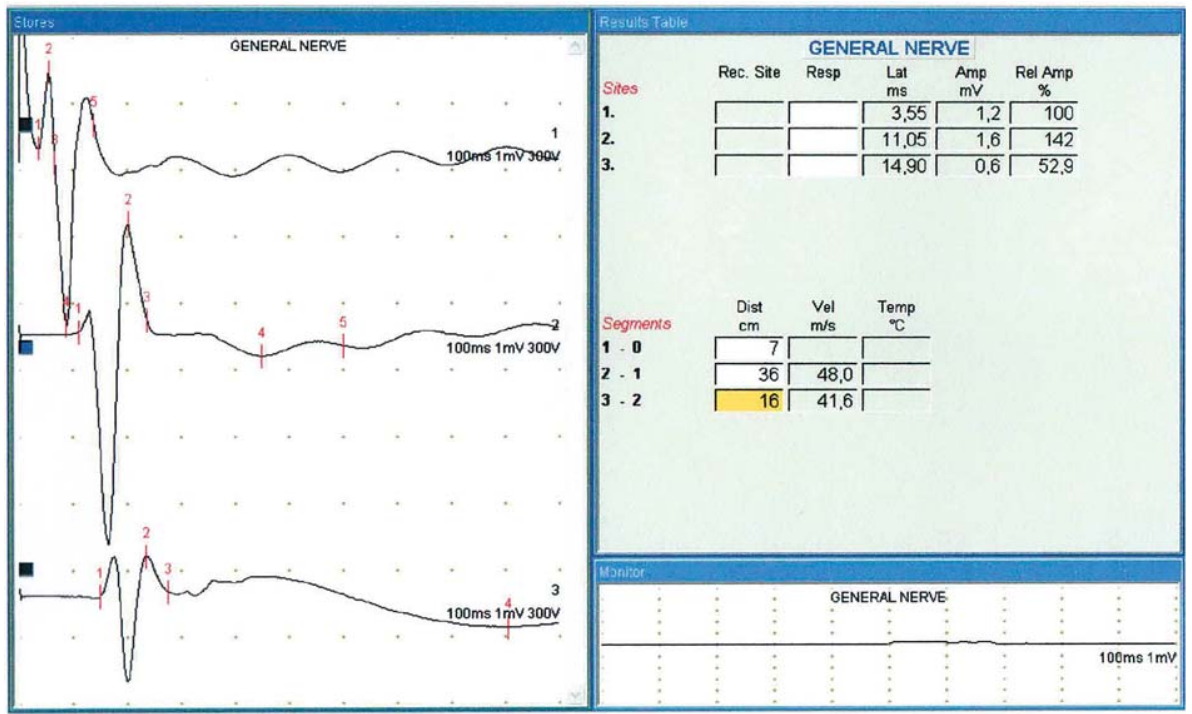

Fig. 2. Left deep peroneal nerve (partial conduction block).

Neurologic examination revealed peroneal walk on the left leg. He could walk on his toes. Dorsiflexion of the left foot was limited. He could squat without problems but could not crouch on full feet; he rather supported on his toes. There was noticeable weakness of the tibial muscle of the left leg, with a clear front edge of the tibia. Patellar reflex was reduced on the left. Achilles tendon reflexes were symmetric and appropriate. The toes of the left foot except for the thumb were in spontaneous dorsiflexion with deformities in terms of dorsiflexion of the proximal phalanx and plantar flexion of the distal phalanx. The arches of both feet were raised, higher on the left foot. Left MEDB was atrophic. There was no sensitivity disturbance.

Electromyoneurography testing showed overt loss of motor neurons in all muscles of his left leg. Milder loss of motor neurons was evident in the area of the right foot. Neurography showed normal MCV in the left nerves analyzed (deep peroneal nerve, tibial nerve, femoral nerve).

Follow up examination was performed after treatment with IVIG in a dose of $0.4 \mathrm{~g} / \mathrm{kg}$ body weight for five days and another IVIG treatment later at a dose of $0.2 \mathrm{~g} / \mathrm{kg}$ for five days. There was an occasional feeling of stiffness in the back of the left knee. The patient also noted some weakness in his left leg but no problems in his hands or right leg. Occasionally, the patient observed twitching muscles in his left thigh. Neurologic examination revealed precise walking on the toes, a little harder on the heel of the left foot. Hypotrophy of the muscle in his left lower leg was noticeable. The patient could squat on full feet and rise from the squat without difficulty. The patient could raise outstretched left foot from the ground lying on his back with resistance (grade 4/5). The upper left leg exhibited a possible myokymia. Left patellar reflex could not be provoked. Achilles tendon reflexes were normal. Left MEDB was less voluminous than the right one. Babinski sign was negative.

Follow up EMNG testing showed normal motor conduction velocity in the analyzed segment of the right ulnar nerve, partial $\mathrm{CB}$ in the analysis of the left deep peroneal nerve and left tibial nerve in proximal segments (distal part of ischiadic nerve), with milder deceleration of motor conduction velocity in all segments (Fig. 2).

\section{Case 3}

I. H., a 26-year-old man, had occasionally felt short-term numbness in the left leg in the past 15 days. The day before admission to the hospital, he felt numbness in his left leg again that lasted for about five minutes and then he felt weakness in his left foot. Since then, there was no feeling of numbness. He thought that there was some recovery of weakness in his left foot. Two years before, he had sustained a traffic accident as a pedestrian, and then he got a kick in the left leg. There were no fractures but his left leg was 


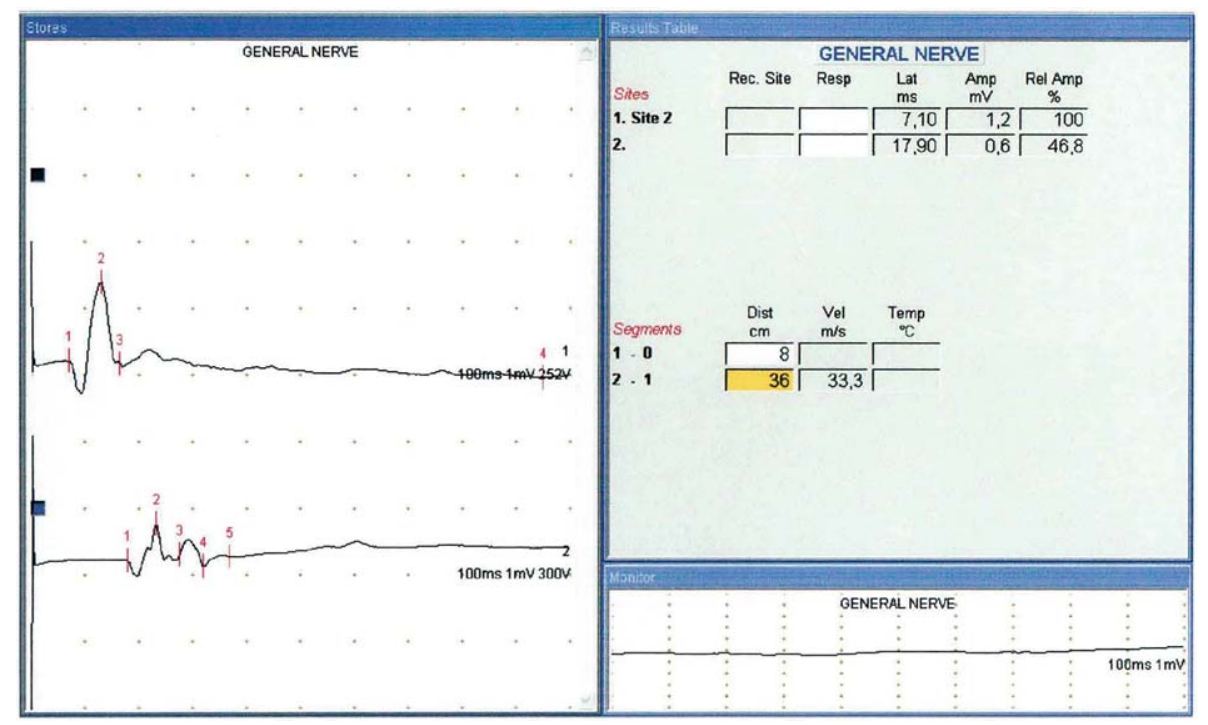

Fig. 3. Left deep peroneal nerve (conduction block).

swollen for a while. He had previously practiced sports (football).

Neurologic testing showed walking that was discretely peroneal on the left. He could walk on his toes, with shortness of the left heel. He could not stand up from full squat on the feet (noting that he could not have done that before either). Achilles tendon was shortened bilaterally. Intraosseous drawing on both feet was emphasized. Minimal dorsiflexion was possible in the left foot, but not to 90 degrees as far as he could be passive. Toes were practically without dorsiflexion. Plantar flexion of the toes and both feet was normal. Left MEDB was atrophic. Patellar reflexes were normal. There were no disturbances of sensitivity. Babinski sign was negative.

Electromyoneurography testing revealed clear loss of motor neurons in the analyzed muscle of his left leg, predominantly distal, most pronounced in MEDB. Neurography analysis pointed to $\mathrm{CB}$ in the analyzed left deep peroneal nerve, with slight reduction in the motor conduction velocity (Fig. 3) and normal neurographs for the left tibial nerve.

One month after the administration of IVIG in a dose of $0.4 \mathrm{~g} / \mathrm{kg}$ body weight for five days, he felt better. His left foot was stronger and more mobile. Neurologic testing revealed walking on heels and walking on his toes was normal. He could squat without difficulty, but he could not do full feet squat without support. Patellar reflexes were normal. Achilles reflexes were normal. Left MEDB was 'wiped out'. There were no disturbances of sensitivity. EMNG showed normal motor conduction through the left deep peroneal nerve and left tibial nerve without $\mathrm{CB}$.

\section{Discussion}

Multifocal motor neuropathy is not as rare clinical entity in practice and should be diagnosed as soon as possible. The patient M.M. gave unreliable information on the onset of symptoms. Probably a month and a half to two months had elapsed from the onset of symptoms to the diagnosis and IVIG administration, while the patient B.A. was examined about six months after the onset of symptoms. It is likely that therapeutic response would have been better had it been applied earlier.

On routine EMNG, one should be careful because the $\mathrm{CB}$ can 'hide' in the proximal or distal parts of the nerves tested ${ }^{4}$. In some patients with $\mathrm{MMN}$ and clear clinical picture, $\mathrm{CB}$ cannot be proven, probably because it is present in the nerves or part of the nerve that cannot be EMNG analyzed at the given moment or when $\mathrm{CB}$ is present in the proximal or distal part of the nerve that has not been tested in routine EMNG. In such cases, it is recommended to use transcortical magnetic stimulation of spinal roots for detection of $\mathrm{CB}$ in the proximal segment of the nerve. In case of the patient M.M., standard EMNG analysis was ex- 
tended and the left partial CB was recorded in ischiadic nerve (tibial nerve) in the segment before the fork, whereas in the patient I.H. clear CB of the left deep peroneal nerve was detected.

In MMN, there is slow progressive or cascading progressive, focal, asymmetric muscle weakness in the area of innervation of at least two peripheral nerves for at least a month. In Case 1, the symptoms lasted for more than a month, with very possible mild slow progression.

If the symptoms and signs are present only in the distribution of one of the peripheral nerves, diagnosis of a possible MMN can be made, which was done in M.M. at the first clinical and EMNG examination. In early stages, the degree of muscle weakness is equal to the degree of muscle atrophy. This phenomenon indicates a primary demyelination disorder rather than axonal lesion. It is interesting that a large number of studies on nerve conduction showed improvement in conductivity after the application of IVIG, although recovery of muscle strength is rarely complete in these patients.

In M.M., there was improvement of $\mathrm{MCV}$ in the ischiadic nerve (tibial nerve), as well as improvement of the strength and mobility in the left foot. In case 2, slight but not complete improvement was recorded after treatment. In I. H., EMNG analysis after IVIG was practically normal and indicated clinical recovery. The curiosity with I.H. was that clear CB was found only in this patient.

Multifocal motor neuropathy must be distinguished from Lewis-Sumner syndrome (LS) and the primary difference is the absence of sensory symptoms in $\mathrm{MMN}$, whereas LS shows significant presence of sensory symptoms, often associated with neuropathic pain. Therefore, neurographic detection of a reduced potential in a variety of sensory nerves is the most realistic criterion to differentiate LS from MMN. The patient M.M. felt slight numbness in the left foot at the beginning of the appearance of symptoms, whereas I.H. stated that he had occasionally felt short-term numbness in the left leg for 15 days prior to admission in the hospital. The day before admission to the hospital, he felt numbness again in his left leg for about five minutes, with the appearance of weakness in the left foot.

Lewis-Sumner syndrome is characterized by the absence of anti-GM1 antibodies, and proteins in the cerebrospinal fluid are often increased. In MMN, there may be a minor sensory deficit in terms of mild pallesthesia in the legs ${ }^{4}$. Unlike LS, patients with MMN have no positive response to the treatment with corticosteroids and plasmapheresis. Studies have recorded better treatment response in younger patients. In a number of uncontrolled studies, some patients showed positive therapeutic response to treatment with cyclophosphamide, interferon beta-1a, cyclosporine, methotrexate and azathioprine ${ }^{2,4,5,8}$.

Some studies suggest that the frequency of other autoimmune diseases is higher in patients with MMN (more pronounced in women) and in close family members of patients than in control group. It has been observed that there is a higher frequency of HLADRB1* 15 in these patients and that the characteristics of the disease are associated with particular HLA types ${ }^{9}$.

\section{Conclusion}

Multifocal motor neuropathy is a rare and disabling disease. In patients with MMN, muscle weakness is the consequence of $\mathrm{CB}$, which leads to secondary axonal degeneration. Consequently, the aim of the treatment is to reverse $\mathrm{CB}$ at early stages of the disease. High-dose immunoglobulin is for now the only therapy with proven efficiency in MMN patients by providing transient improvement of muscle strength, but long-term follow up studies show a progressive motor decline. We presented our three cases of MMN with positive response to IVIG. Diagnosis was based on EMNG tests, clinical features and positive response to treatment with immunoglobulins. According to the European Federation of Neurological Societies guidelines, MMN is a clearly defined clinical entity and it should be diagnosed on time and treated with IVIG. In addition to the application of immunoglobulin, an additional therapeutic option is continuous physical therapy.

\section{References}

1. Nguyen TP, Chaudhry V. Multifocal motor neuropathy. Neurol India. 2011;59(5):700-6. doi: 10.1186/1752-0509-5-179.

2. Meuth SG, Kleinschnitz C. Multifocal motor neuropathy: update on clinical characteristics, pathophysiology concepts and 
therapeutic options. Eur Neurol. 2010;63(4):193-204. doi: $10.159 / 000282734$.

3. Sinanović O. Imunološki posredovane neuromišićne bolesti. Neurol Croat. 2010;59(Suppl 1):61-72. (in Croatian)

4. Schulte-Mattler WJ, Müller T, Georgiadis D, Kornhuber ME, Zierz S. Length dependence of variables associated with temporal dispersion in human motor nerves. Muscle Nerve. 2001; 24:527-33.

5. Garg N, Park SB, Vucic S, Yiannikas C, Spies J, Howells J, Huynh W, Matamala MJ, Krishnan VA, Pollard DJ, Cornblath RD, Reilly MM, Kierman CM. Differentiating lower motor neuron syndromes. J Neurol Neurosurg Psychiatry. 2017;88: 474-83. doi: 10.136/jmp-2016-313526.

6. Koski CL. Treatment of multifocal motor neuropathy with intravenous immunoglobulin. J Clin Immunol. 2014;Suppl 1: S127-S131. doi: 10.1007/s10875-014-0016-5.
7. Stangel M, Gold R, Pittrow D, Baumann U, Borte M, Fasshauer M, Hensel M, Huscher D, Reiser M, Sommer C. Treatment of patients with multifocal motor neuropathy with immunoglobulins in clinical practice: the SIGNS registry. Ther Adv Neurol Disord. 2016;9(3):165-79. doi: 10.1177/1756285616629869.

8. van Schalk N, Bouche P, Illa I, Leger JM, Van den Berg P, Cornblath DR, Evers E, Hadden RDM, Hughes RAC, Koski CL, Nobile-Orazio E, Pollard J, Sommer C, van Doorn PA. Multifocal motor neuropathy. In: Hughes R, Brainin M, Gilhus NE (eds). European Handbook of Neurological Management. Oxford: Blackwell Publishing, 2006; p. 354-61.

9. Sutedja NA, Otten HG, Cats EA, Piepers S, Veldnik JH, van der Pol WL, van den Berg LH. Increased frequency of HLA-DRB1*15 in patients with multifocal motor neuropathy. Neurology. 2010;74:828-32. doi: 10.1212/WNL.0b013e3181d3e2f6.

Sažetak

\title{
MULTIFOKALNA MOTORNA NEUROPATIJA: PRIKAZI SLUČAJA
}

\author{
E. Jusuforić, O. Sinanović, S. Zukic, A. Burina, Z. Džinić Jusufović i A. Šakić
}

Multifokalna motorna neuropatija (MMN) je kronična demijelinizirajuća neuropatija koja je obilježena multifokalnom distribucijom; zahvaćanjem samo motornih živčanih vlakana dvaju ili više perifernih živaca, uz odsutnost znakova lezije gornjega motornog neurona; kroničnim, ponekad kaskadnim progresivnim tijekom; demijelinizacijom s djelomičnim blokom motornog provođenja; imunosno posredovanom patogenezom i dobrim odgovorom na terapiju intravenskim imunoglobulinom (IVIG). Dijagnoza se postavlja na osnovi kliničke slike, laboratorijskih i elektrofizioloških parametara. Steroidi su neučinkoviti kod MMN, a mogu dovesti i do pogoršanja bolesti. Slično, terapijska izmjena plazme je zanemarivo učinkovita u ovoj neuropatiji. Međutim, više od $80 \%$ bolesnika s MMN imaju poboljšanje nakon IVIG. U radu prikazujemo naša tri slučaja MMN s pozitivnim odogovorom na IVIG.

Ključne riječi: Polineuropatije; Demijelinizacijske bolesti; Periferni živci; Motorički neuroni; Imunoglobulini, intravenski 